\title{
Hubungan Antara Differential settlement Dengan Kekuatan Elemen Struktur Balok Dan Kolom

\author{
(Studi Kasus Hotel Sleeper Space Semarang)
}

\author{
Anita Carolina ${ }^{1}$, Eric Hansen Irawan ${ }^{2}$, \\ Hermawan $^{3}$, Budi Setiyadi ${ }^{4}$ \\ email: 400.yoo@gmail.com
}

\begin{abstract}
Program Studi Teknik Sipil, Fakultas Teknik, Unika Soegijapranata, Semarang, Universitas Katolik Soegijapranata; Jl. Pawiyatan Luhur IV/1 Bendan Dhuwur Semarang 50234, 024-8441555
\end{abstract}

\begin{abstract}
Abstrak
Dalam sebuah perencanaan gedung, perencanaan struktur merupakan unsur terpenting agar tidak terjadi kesalahan-kesalahan konstruksi, seperti penurunan bangunan. Beberapa faktor yang mempengaruhi besarnya penurunan, yaitu: kondisi tanah, berat bangunan, kesalahan perencanaan, dan tingkat muka air tanah. Penelitian dengan judul 'Hubungan Differential settlement Dengan Kekuatan Elemen Struktur Balok dan Kolom (Studi Kasus Hotel Sleeper Space Semarang)', bertujuan agar perencanaan komponen struktur mampu menahan terjadinya penurunan. Penelitian ini menggunakan perangkat lunak ETABS 2018 v18.0.2. Penelitian dimulai dengan menentukan gedung yang akan diteliti, analisa penurunan bangunan menggunakan bantuan perangkat lunak ETABS 2018 v18.0.2, menggunakan 5 variabel penurunan dalam centimeter, dan pada akhirnya didapatkan besaran momen pada balok dan kolom untuk menentukan kemampuan Hotel Sleeper Space Semarang apabila mengalami penurunan.
\end{abstract}

Kata kunci : Differential settlement, gedung, kekuatan struktur

\begin{abstract}
In a building plan, structural planning is the most important element so that construction errors do not occur, such as building subsidence. Several factors affect the magnitude of the settlement, namely: soil conditions, building weight, planning errors, and ground water level. The research entitled 'The Relationship of Differential settlement with the Strength of Beam and Column Structural Elements (Case Study of Hotel Sleeper Space Semarang)', aims to design structural components to be able to withstand the occurrence of settlement. This study uses the ETABS 2018 v18.0.2 software. The research begins by determining the building to be studied, analyzing the settlement of the building using the help of ETABS 2018 v18.0.2 software, using 5 settlement variables in centimeters, and in the end, the magnitude of the moment in the beam and column is obtained to determine the ability of Hotel Sleeper Space Semarang if it decreases.
\end{abstract}

Keywords: Differential settlement, building, structural strength

\begin{tabular}{lll} 
1. PENDAHULUAN & pembangunan di Kota Semarang, seperti: \\
Latar Belakang & gedung perkantoran, swalayan, hotel, dan \\
Kepadatan & penduduk & $\begin{array}{l}\text { lain sebagainya. Perencanaan } \\
\text { menyebabkan pesatnya }\end{array}$ \\
& perencanaan & pembangunan memerlukan pemilihan \\
\hline
\end{tabular}

G-SMART Jurnal Teknik Sipil Unika Soegijapranata Semarang | ISSN : 2620-5297 (online)

Volume 5 | Nomor 1 | Juni 2021 
jenis pondasi yang tepat, agar dapat digunakan dalam jangka panjang dan dapat meminimalisir penurunan tanah. Hal ini dikarenakan, pondasi berfungsi menyalurkan beban bangunan diatasnya ke dalam tanah, dan harus mampu menahan gaya - gaya luar (gaya angin, gaya gempa, dan lain - lain).

Menurut Lastiasih dan Mochtar (2008), tahapan dalam pemilihan jenis pondasi seringkali mengalami kesulitan, perencana dihadapkan dengan kasus bangunan dengan tinggi bangunan yang tanggung (3 - 8 lantai) atau daya dukung tanah relatif rendah. Kesalahan dalam pemilihan pondasi akan menyebabkan hal - hal yang dijabarkan sebagai berikut:

a) Lantai bergelombang, pecah, dan retak,

b) Penurunan atap dan bagian bangunan lainnya,

c) Kerusakan pada dinding yang menyebabkan retak atau miring,

d) Biaya rancangan anggaran bangunan meningkat,

e) Penurunan muka tanah secara merata (uniform settlement).

Penurunan muka tanah diakibatkan hal - hal yang dijabarkan sebagai berikut:

a) Bukaan bawah tanah (tambang, terowongan, galian, dan lain sebagainya),

b) Aktivitas tektonik,

c) Pemompaan air tanah dan pengambilan gas alam yang berlebihan.

d) Beban yang berat di atasnya (overburden, bangunan, dan lain sebagainya).

Beberapa aspek yang perlu diperhatikan dalam mencegah penurunan yang dijabarkan sebagai berikut:

a) Gedung harus cukup kaku dalam mencegah penurunan yang terjadi akibat konsolidasi tanah dasar, sehingga penurunan yang terjadi hanya menghasilkan penurunan secara merata. Jenis penurunan diperlihatkan pada Gambar 1.1.

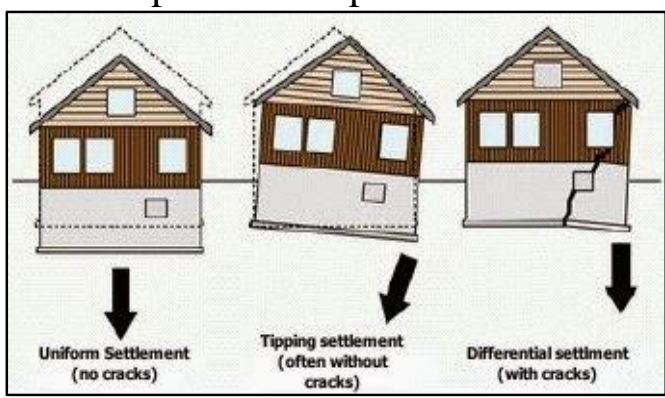

Gambar 1.1 Jenis Penurunan (Sumber: https://www.geotech.hr/en/differentia

1 settlements/, diakses pada 20 September 2020, pukul 16.30 WIB)

b) Jumlah reaksi total tanah dasar harus sama dengan berat gedung,

c) Toleransi penurunan harus terpenuhi, untuk bangunan beton $0,002 \mathrm{~s} / \mathrm{d}$ 0,003 , dan untuk bangunan baja 0,006 s/d 0,008.

Proses perhitungan struktur untuk meminimalisir penurunan bangunan (settlement) memerlukan program komputer analisis struktur yang kompeten. Program komputer yang lazim digunakan adalah SAP2000, ETABS, dan lain sebagainya. Setiap program memiliki kelebihan dan kekurangan dalam penggunaannya. Penelitian akan menggunakan software ETABS v18.0.2 disebabkan program ETABS dirancang untuk menganalisis high rise building. Berdasarkan ketersediaan data yang dimiliki, Hotel Sleeper Space Semarang akan dianalisis menggunakan variabel penurunan $1 \mathrm{~cm}, 2 \mathrm{~cm}, 3 \mathrm{~cm}, 4 \mathrm{~cm}$, dan 5 $\mathrm{cm}$ pada kolom baris as A. Proses analisis dilakukan untuk meminimalisir kesalahan - kesalahan yang mungkin terjadi. 


\section{Tujuan Penelitian}

Adapun tujuan yang ingin dicapai dalam penelitian ini, dijabarkan sebagai berikut:

a) Mengevaluasi kekuatan balok B2i, balok B3i, dan balok B4 terhadap perubahan momen akibat Differential settlement.

b) Mengevaluasi kekuatan kolom KS1, kolom KS2, dan kolom KT terhadap perubahan momen akibat terjadinya Differential settlement.

\section{Batasan Masalah}

Pembatasan terhadap masalah yang dianalisis dalam penelitian ini, dijabarkan sebagai berikut:

a) Data gedung yang digunakan dalam penelitian ini, merupakan data Tugas Akhir yang dibuat oleh Harjanti dan Hendrawan (2020) dengan judul 'Perencanaan Struktur Bangunan Hotel Sleeper Space Semarang' yang berlokasi di Jalan Letjen Suprapto No 44-46 Semarang.

b) Proses analisis tidak akan merubah dimensi struktur Hotel Sleeper Space Semarang.

c) Beban yang bekerja adalah beban mati $\left(\mathrm{W}_{\mathrm{D}}\right)$, beban hidup $\left(\mathrm{W}_{\mathrm{L}}\right)$, dan beban gempa $\left(\mathrm{W}_{\mathrm{E}}\right)$. Perhitungan beban hujan $\left(\mathrm{W}_{\mathrm{R}}\right)$ diabaikan disebabkan gedung bertingkat menggunakan dak beton dan memiliki talang air sehingga tidak terjadi genangan air.

d) Penelitian akan menggunakan program ETABS v18.0.2 secara tiga dimensi (3D).

e) Penurunan bangunan secara tidak merata pada Hotel Sleeper Space Semarang terjadi pada kolom baris as A nomor 1 - nomor 8 .

f) Hotel Sleeper Space Semarang dianalisis dengan mutu bahan yang dijabarkan sebagai berikut:

1. Kuat tekan beton $\left(f_{c}{ }^{\prime}\right)=33,2 \mathrm{MPa}$,
2. Teg. leleh tulangan utama $\left(\mathrm{f}_{\mathrm{y}}\right)$ $=400 \mathrm{MPa}$,

3. Teg. leleh tulangan geser $\left(\mathrm{f}_{\mathrm{ys}}\right)$ $=240 \mathrm{MPa}$,

4. Berat jenis beton bertulang $=2400$ $\mathrm{Kg} / \mathrm{m} 3$.

g) Balok yang akan dianalisis dalam penelitian ini adalah B3i, B2i, dan B4.

h) Kolom yang akan dianalisis dalam penelitian ini adalah $\mathrm{KS} 1, \mathrm{KS} 2$, dan KT.

\section{TINJAUAN PUSTAKA}

2.1 Penurunan (Differential settlement)

Menurut Pranoto dan Setiabudi

(2017), penurunan bangunan secara tidak merata dapat terjadi, apabila tanah di bawah bangunan tidak homogen, akibat pembentukan tanah secara alamiah atau akibat proses cut and fill. Kondisi tanah yang tidak homogen wajib menggunakan pondasi yang kedalamannya mencapai tanah keras. Differential settlement menyebabkan tegangan ekstra pada komponen bangunan atas atau bangunan bawah yang menimbulkan retakan atau patah apabila melampaui tegangan ijin.

\subsection{Kekuatan Struktur}

Menurut Zuhri (2011), kekuatan merupakan kemampuan elemen dan komponen struktur yang bekerja secara vertikal atau horizontal dalam menahan beban - beban yang timbul. Komponen struktur bangunan vertikal berupa kolom dan komponen struktur horizontal berupa struktur lantai dan balok.

\subsection{Balok dan Kolom}

Menurut McCormac, C.J. (2003), balok adalah elemen struktur yang didesain untuk menahan gaya yang bekerja secara transversal terhadap sumbunya sehingga mengakibatkan terjadinya lenturan. Balok dapat mengalami kondisi 
tekan dan tarik, karena adanya pengaruh gaya lateral.

Menurut McCormac, C.J. (2003), kolom berfungsi menahan gaya vertikal dan momen lentur yang akan disebarkan menuju pondasi bangunan. Apabila terjadi kegagalan pada kolom, maka dapat berakibat keruntuhan komponen struktur yang lain atau bahkan terjadi keruntuhan total pada keseluruhan struktur bangunan.

\subsection{Software ETABS v18.0.2}

Penelitian ini menggunakan program Extended Three Dimensional Analysis of Building Systems (ETABS). Program komputer ini dinilai sudah memenuhi standar untuk menganalisis struktur di Indonesia.Program ETABS merupakan program komputer yang dikhususkan untuk menganalisi high rise building dari frame baja, frame beton, balok komposit, baja rangka batang, dan dinding geser. Structure Analysis Program (SAP2000) merupakan salah satu program komputer yang digunakan untuk menganalisis struktur secara statik atau dinamik dari desain penampang beton atau baja. Penggunaan SAP2000 didesain secara khusus untuk menganalisis jembatan, bendungan, stadion dan struktur untuk industri.

Menurut Kusuma (2017), beberapa keunggulan ETABS jika dibandingkan dengan SAP2000 dijabarkan sebagai berikut:

a. Spesifikasi data gedung dapat diinput lebih mudah, meliputi:

1. Jumlah lantai,

2. Ketinggian antar lantai yang sama,

3. Ketinggian lantai bawah,

4. Penentuan satuan yang akan digunakan.

b. Setting 'Similar Story', untuk kasus dimana lantai yang didesain sama dengan lantai yang lain. Setting 'One
Story', untuk kasus dimana lantai yang didesain berbeda dengan lantai yang lain.

\section{METODE PENELITIAN 3.1 Tahapan Penelitian}

Tahapan dari penelitian dimulai dengan penyusunan latar belakang, rumusan masalah, tujuan penelitian, mencari data gedung (minimal lima lantai) yang sudah didirikan atau masih dalam perencanaan mencakup hasil permodelan ETABS, menentukan variabel besar penurunan sebagai perbandingan, dan kemudian dilanjutkan dengan studi pustaka yang berguna untuk mendapatkan pengetahuan terkait perubahan momen yang terjadi pada balok dan kolom akibat adanya penurunan. Analisis akan dilakukan menggunakan variabel penurunan $1 \mathrm{~cm}, 2 \mathrm{~cm}, 3 \mathrm{~cm}, 4 \mathrm{~cm}$, dan 5 $\mathrm{cm}$ di ETABS v18.0.2 sebanyak 2 kali yang dijabarkan sebagai berikut:

a) Analisis struktur tanpa mengubah beban hidup,

b) Analisis struktur dengan beban hidup dianggap 0.

Elemen struktur yang dianalisis pada Hotel Sleeper Space Semarang adalah balok B2i, balok B3i, balok B4, kolom KS1, kolom KS2, dan kolom KT. Hasil dari analisis tersebut didapatkan data sekunder yang berupa nilai - nilai momen pada balok dan kolom yang sudah ditentukan. Setelah melalui proses analisis, dilakukan penyusunan kesimpulan dan saran. Tahapan alur penelitian diperlihatkan pada Gambar 3.1. 


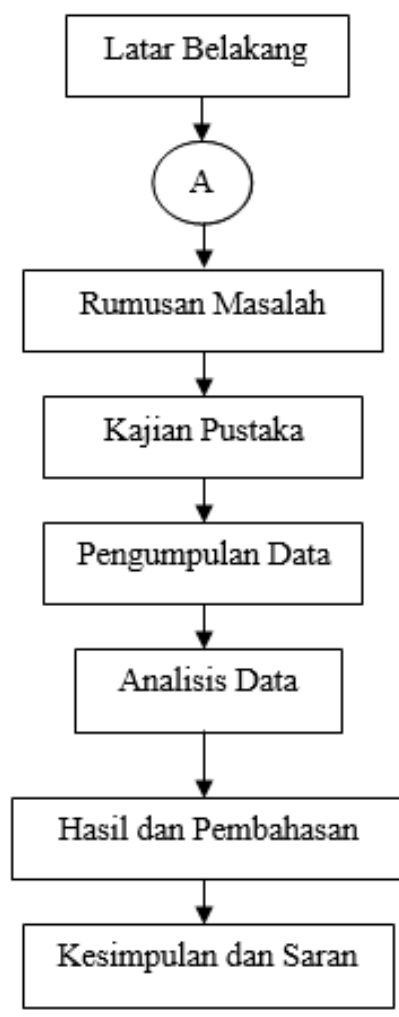

Gambar 3.1 Tahapan Alur Penelitian

\subsection{Data Penelitian}

Penurunan pada Hotel Sleeper Space Semarang terjadi pada kolom baris as $\mathrm{A}$ nomor 1 - nomor 8 , diperlihatkan pada Gambar 3.2.

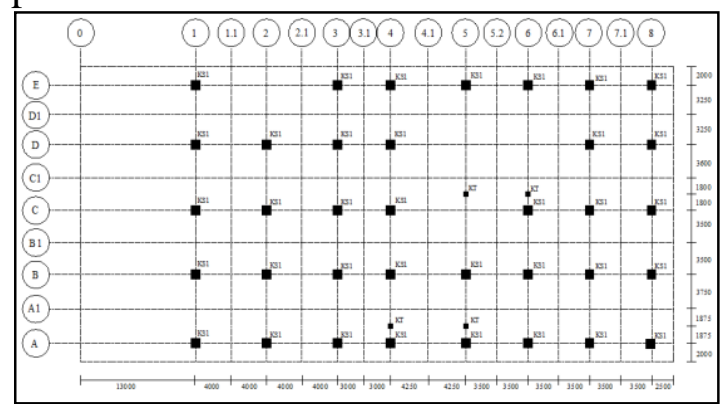

Gambar 3.2 Denah Lantai Kolom GF

Hotel Sleeper Space Semarang (Sumber: Harjanti dan Hendrawan, 2020)

Data dimensi struktur Hotel Sleeper Space Semarang diperlihatkan pada Tabel 3.1.
Tabel 3.1 Dimensi Struktur Hotel Sleeper Space Semarang

\begin{tabular}{llll}
\hline $\begin{array}{l}\text { Strukt } \\
\text { ur }\end{array}$ & Kode & $\begin{array}{l}\text { Ukuran } \\
(\mathrm{cm})\end{array}$ & $\begin{array}{l}\text { Diameter } \\
(\mathrm{mm})\end{array}$ \\
\hline $\begin{array}{l}\text { Tie } \\
\text { Beam }\end{array}$ & TB & $800 / 800$ & 29 \\
Balok & BA & $450 / 600$ & 25 \\
& BT & $450 / 500$ & 19 \\
& B1e & $500 / 700$ & 22 \\
& B1i & $500 / 700$ & $25 \& 22$ \\
& B2e & $500 / 750$ & $25 \& 22$ \\
& B2i & $500 / 750$ & $25 \& 29$ \\
& B3e & $600 / 750$ & 25 \\
& B3i & $600 / 750$ & $25 \& 29$ \\
& B4 & $750 / 900$ & 29 \\
Kolom & KS1 & $900 / 900$ & 29 \\
& KS2 & $850 / 850$ & 29 \\
& KS3 & $800 / 800$ & 29 \\
& KS4 & $750 / 750$ & 29 \\
& KTB & $600 / 600$ & 25 \\
& KTGF & $600 / 600$ & 25 \\
& KT02TOP & $600 / 600$ & 25 \\
\hline (Sumber: Harjanti dan Hendrawan, 2020)
\end{tabular}

\subsection{Teknik Analisis Data}

Teknik analisis data yang digunakan pada penelitian ini dapat dijabarkan sebagai berikut:

a) Setelah mendapatkan data sekunder berupa nilai momen pada balok B2i, balok B3i, balok B4, kolom KS1, kolom KS2, dan kolom KT, dapat dibuat grafik hubungan antara momen dan penurunan, seperti yang diperlihatkan pada Gambar 3.3.

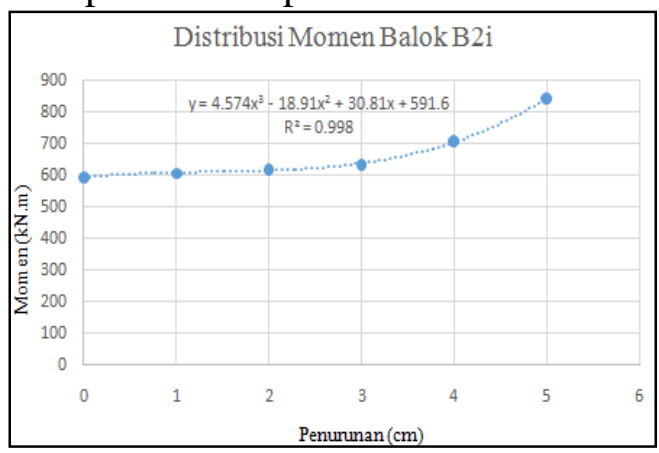

Gambar 3.3 Hubungan Antara

Penurunan (x) dan Momen Ultimit (y) pada Balok B2i 
Nilai R2 menggambarkan kesempurnaan hubungan antara sumbu $\mathrm{x}$ (penurunan) dan sumbu $\mathrm{y}$ (nilai momen) pada Hotel Sleeper Space, sedangkan rumus statistik menggambarkan besarnya momen akibat terjadinya penurunan pada Hotel Sleeper Space.

b) Setelah mendapatkan hubungan antara penurunan (x) dan momen ultimit (y), dilakukan analisis mengenai perbandingan jumlah tulangan yang dibutuhkan sebelum mengalami penurunan dan sesudah mengalami penurunan pada kolom baris as A nomor 1 - nomor 8. Balok dinyatakan tidak aman, apabila melebihi jumlah tulangan saat sebelum mengalami penurunan. Formula yang digunakan untuk perhitungan tulangan balok diperlihatkan pada Persamaan 3.1, Persamaan 3.2, Persamaan 3.3, Persamaan 3.4, Persamaan 3.5, Persamaan 3.6, Persamaan 3.7, Persamaan 3.8, Persamaan 3.9, Persamaan 3.10, Persamaan 3.11, Persamaan 3.12, Persamaan 3.13, Persamaan 3.14, Persamaan 3.15, dan Persamaan 3.16. (McCormac, C.J., 2003)

$\mathrm{M}_{\text {maks }}$ pasang tulangan $=\mathrm{M}_{\mathrm{u}} \times 100$

$M_{\text {maks }}$ eksternal $=\frac{M_{\text {maks }} \text { pemasangan tulangan }}{1.000}$

$\beta=0,85-0,05 \times \frac{\left(\mathrm{f}_{\mathrm{c}}^{\prime}-4.000\right) \mathrm{P}_{\mathrm{si}}}{1.000}$

$\mathrm{A}_{\mathrm{s}}{ }^{\prime}=\left[0,25 \times 3,14 \times\left(\varnothing^{2}\right)\right] \times 2$

$\mathrm{d}=\mathrm{h}_{\mathrm{b}}-50-13-\frac{\varnothing}{2}$

$\mathrm{d}_{\mathrm{s}}=\mathrm{h}_{\mathrm{b}}-\mathrm{d}$

Maksimal jumlah batang $=\frac{\mathrm{b}_{\mathrm{w}}-70}{\varnothing+30}$

$\mathrm{A}_{\mathrm{s}}=\left[0,25 \times 3,14 \times\left(\varnothing^{2}\right)\right] \times$ tulangan dipakai(3.8)

Persamaan $A=0,85 \times f_{c}{ }^{\prime} \times b_{w}$

Persamaan $B=0,003 \times E_{s} \times\left(A_{s}{ }^{\prime}-A_{s}\right) \times f_{y}(3.10)$

Persamaan $\mathrm{C}=-0,003 \times \mathrm{E}_{\mathrm{s}} \times \mathrm{A}_{\mathrm{s}}{ }^{\prime} \times \beta \times \mathrm{d}_{\mathrm{s}}^{\prime}(3.11)$

$$
\begin{aligned}
& \mathrm{a} 1=-\mathrm{B}+\sqrt{\frac{\mathrm{B}^{2}-(4 \times \mathrm{A} \times \mathrm{C})}{(2 \times \mathrm{A})}} \\
& \mathrm{M}_{\mathrm{n}}=0,85 \times \mathrm{f}_{\mathrm{c}}{ }^{\prime} \times \mathrm{b}_{\mathrm{w}} \times \mathrm{a} 1 \times\left[\left(\frac{\mathrm{d}-\mathrm{a} 1}{2}\right)+\mathrm{A}_{\mathrm{s}}^{\prime}\right](3.13) \\
& \times\left(d-d^{\prime}\right) \\
& \mathrm{M}_{\mathrm{u}}=\mathrm{M}_{\mathrm{n}} \times 0,8 \\
& \mathrm{M}_{\text {kapasitas }}=\frac{\mathrm{M}_{\mathrm{u}}}{10} \\
& \mathrm{M}_{\text {kap }}>\frac{\mathrm{M}_{\text {maks }} \mathrm{eksternal}}{0,8}
\end{aligned}
$$

Keterangan:

$\mathrm{M}_{\mathrm{u}} \quad$ : Momen ultimit (kN.m)

$\varnothing \quad$ : Diameter (mm)

$\mathrm{A}_{\mathrm{s}} \quad$ : Luas tulangan longitudinal $\left(\mathrm{mm}^{2}\right)$

$\mathrm{h}_{\mathrm{b}} \quad$ : Tinggi balok $(\mathrm{mm})$

$b_{\mathrm{w}} \quad$ : Lebar balok (mm)

$\mathrm{E}_{\mathrm{s}} \quad$ : Modulus elastisitas (MPa)

$\mathrm{M}_{\mathrm{n}} \quad$ : Momen nominal

$\mathrm{f}_{\mathrm{c}} \quad$ : Kuat tekan beton (MPa)

$\mathrm{f}_{\mathrm{y}} \quad$ : Tegangan leleh tulangan utama (MPa)

$\mathrm{d}_{\mathrm{s}} \quad$ : Jarak pusat luasan tulangan tarik

$\mathrm{f}_{\mathrm{s}} \quad$ : Kuat lentur rencana $(\mathrm{MPa})$

c) Analisis kolom dilakukan menggunakan diagram interaksi kolom yang diperlihatkan pada Gambar 3.4.

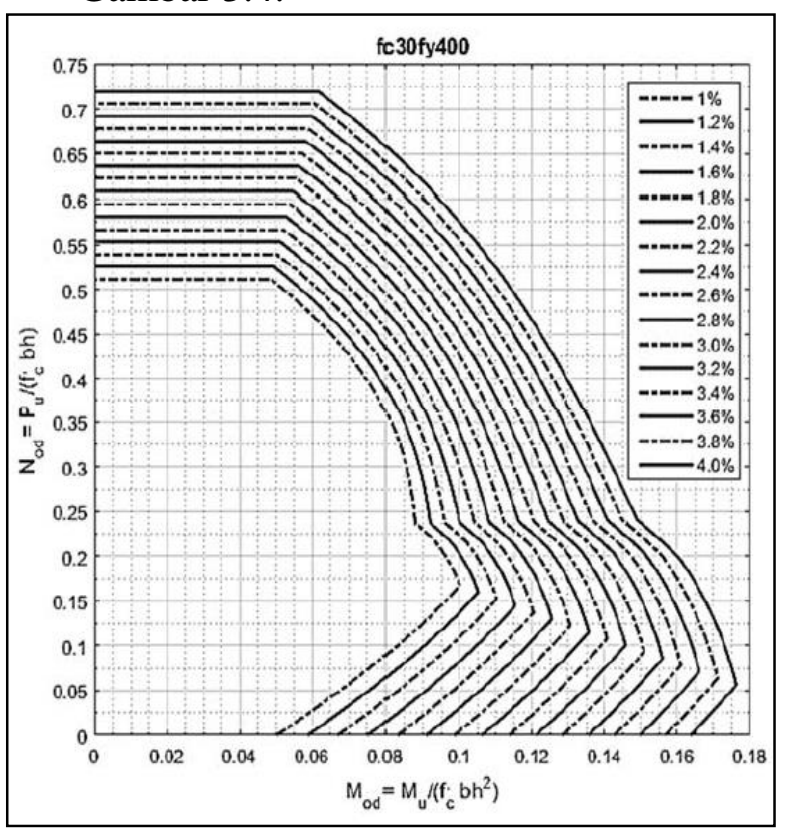

Gambar 3.4 Diagram Interaksi Kolom (Arfiadi, 2016)

Setiap penurunan yang terjadi pada kolom Hotel Sleeper Space Semarang 
menghasilkan ordinat untuk ditempatkan pada Gambar 3.4. Formula yang digunakan untuk perhitungan ordinat diperlihatkan pada Persamaan 3.17 dan Persamaan 3.18. (McCormac, C.J., 2003)

Ordinat $\mathrm{x}=\frac{\mathrm{M}_{\mathrm{u}}}{\mathrm{f}_{\mathrm{c}}{ }^{\prime} \times \mathrm{b}_{\mathrm{w}} \times \mathrm{h}_{\mathrm{b}}{ }^{2}}$

Ordinat $y=\frac{\mathrm{P}_{u}}{\mathrm{f}_{\mathrm{c}} \times \mathrm{b}_{\mathrm{w}} \times \mathrm{h}_{\mathrm{b}}}$

Keterangan:

$\mathrm{M}_{\mathrm{u}} \quad$ : Momen ultimit (kN.m)

$\mathrm{P}_{\mathrm{u}} \quad$ : Beban ultimit (kN.m)

$\mathrm{h}_{\mathrm{b}} \quad$ : Tinggi balok (mm)

$\mathrm{b}_{\mathrm{w}} \quad$ : Lebar balok (mm)

Kolom dinyatakan masih aman apabila ordinat belum menyentuh garis $\rho$ (rho) diagram interaksi dan kolom dinyatakan tidak aman apabila pada saat penurunan $1 \mathrm{~cm}-5 \mathrm{~cm}$ titik ordinat menyentuh atau melebihi garis $\rho$ (rho) diagram interaksi. Perhitungan tulangan kolom diperlihatkan pada Persamaan 3.19. (McCormac, C.J., 2003)

$\mathrm{A}_{\mathrm{s}}=\rho \times \mathrm{b}_{\mathrm{w}} \times \mathrm{h}_{\mathrm{b}}$

Keterangan:

$\mathrm{A}_{\mathrm{s}} \quad$ : Luas tulangan longitudinal $\left(\mathrm{mm}^{2}\right)$

$\rho$ : Rasio baja tulangan yang diperlukan

$\mathrm{h}_{\mathrm{b}} \quad$ : Tinggi balok $(\mathrm{mm})$

$b_{\mathrm{w}}$ : Lebar balok (mm)

d) Proses analisis dilakukan sebanyak dua kali dengan cara:

1. Analisis struktur tanpa mengubah beban hidup,

2. Analisis struktur dengan beban hidup dianggap 0 .

Hal ini dilakukan untuk mengukur seberapa kuat balok B2i, balok B3i, balok B4, kolom KS1, kolom KS2, dan kolom KT dalam menopang Hotel Sleeper Space meskipun tidak ada lagi beban hidup (manusia, beban bergerak, dan lain sebagiainya) didalamnya.

\section{HASIL DAN PEMBAHASAN}

a) Berdasarkan analisis struktur elemen gedung (Balok B2i, Balok B3i, dan Balok B4) menggunakan ETABS v18.0.2, didapatkan nilai koefisien korelasi (R2) yang didapat > 95\%. Menurut Hadi (1993), hal ini menggambarkan kesempurnaan hubungan antara sumbu x (penurunan) dan sumbu y (nilai momen) pada Hotel Sleeper Space Semarang.

Perhitungan jumlah tulangan balok yang dibutuhkan setelah mengalami penurunan, menunjukkan bahwa Balok B3i tidak mampu menahan penurunan (differential settlement) yang terjadi. Hal ini disebabkan perubahan momen yang sangat tinggi pada saat mengalami penurunan $1 \mathrm{~cm}$.

Perhitungan jumlah tulangan balok yang dibutuhkan setelah mengalami penurunan, apabila beban hidup dianggap 0 , menunjukkan bahwa Balok B3i tetap tidak mampu menahan penurunan (differential settlement) yang terjadi. Oleh karena itu, dapat disimpulkan bahwa faktor beban hidup berpengaruh kecil pada elemen struktur balok yang mengalami penurunan (differential settlement).

b) Berdasarkan analisis struktur elemen gedung (Kolom KS1, Kolom KS2, dan ) menggunakan 
ETABS v18.0.2, didapatkan nilai koefisien korelasi (R2) yang didapat > 95\%. Menurut Hadi (1993), hal ini menggambarkan kesempurnaan hubungan antara sumbu x (penurunan) dan sumbu y (nilai momen) pada Hotel Sleeper Space Semarang.

Perhitungan kekuatan kolom menggunakan diagram interaksi, menunjukkan bahwa Kolom KT tidak mampu menahan penurunan (differential settlement) yang terjadi. Hal ini disebabkan perubahan momen yang sangat tinggi pada saat mengalami penurunan $1 \mathrm{~cm}$.

Perhitungan kekuatan kolom menggunakan diagram interaksi, apabila beban hidup dianggap 0 , menunjukkan bahwa Kolom KT tetap tidak mampu menahan penurunan (differential settlement) yang terjadi. Oleh karena itu, dapat disimpulkan bahwa faktor beban hidup berpengaruh kecil pada elemen struktur balok yang mengalami penurunan (differential settlement).

\section{KESIMPULAN}

Pada penelitian mengenai Hubungan Antara Differential Settlement Dengan Kekuatan Elemen Struktur Balok Dan Kolom (Studi Kasus Hotel Sleeper Space Semarang), maka diperoleh beberapa kesimpulan sebagai berikut:

a. Nilai koefisien korelasi pada Balok B2i, Balok B3i, dan Balok B4 lebih dari $95 \%$. Hal ini menggambarkan kesempurnaan hubungan antara sumbu $x$ (penurunan) dan sumbu $y$ (nilai momen) pada Hotel Sleeper Space. Hasil analisis struktur Balok B2i, Balok B3i, dan Balok B4 Hotel Sleeper Space Semarang, menunjukkan bahwa Balok B3i tidak mampu menahan penurunan (differential settlement) yang terjadi. Hal ini disebabkan perubahan momen yang sangat tinggi pada penurunan 1 $\mathrm{cm}$.

b. Hasil analisis struktur pada Kolom KS1, Kolom KS2, dan Kolom KT Hotel Sleeper Space Semarang, menunjukkan bahwa nilai koefisien korelasi dari setiap kolom lebih dari 95\% dan Kolom KT tidak mampu menahan penurunan (differential settlement) yang terjadi. Hal ini disebabkan perubahan momen yang tinggi sehingga Kolom KT tidak mampu menahan penurunan.

\section{DAFTAR PUSTAKA}

Arfiadi, Y. (2016): Diagram interaksi perancangan kolom dengan tulangan pada empat sisi berdasarkan SNI 2847:2013 dan ACI 318M11.https://www.researchgate.net/publ ication/313579682_DIAGRAM_INT ERAKSI_PERANCANGAN_KOLO M_DENGAN_TULANGAN_PADA _EMPAT_SISI_BERDASARKAN_ SNI_28472013_DAN_ACI_318M11. Diakses pada 20 Januari 2021, Pukul 15.00 WIB

Bella, M.T. dan Latif, O.D. (2014). Analisis settlement konstruksi sarang laba-laba proyek pembangunan Gedung BNI 46 Jalan Dr.Cipto Semarang dengan perkuatan minipile beton menggunakan software plaxis 
versi

8.2.

http://etd.repository.ugm.ac.id/home/ detail_pencarian/72151. Diakses pada 06 Desember 2020, Pukul 14.16 WIB

Hadi, S. (1993): Statistik, Jilid I. Yogyakarta: Yayasan Penerbitan Fakultas Psikologi, Universitas Gajahmada.

https://books.google.co.id/books?id= h2WJuYW79sIC\&printsec=frontcov er\&dq=inauthor:\%22Prof.Drs.+Sutris no+Hadi, + MA $\% 22 \& h l=i d \& s a=X \& v$ ed=2ahUKEwjXndv_zfruAhW8IbcA HWynB28Q6AEwAHoECAAQAg\# $\mathrm{v}=$ onepage $\& \mathrm{q} \& \mathrm{f}=$ false. Diakses pada tanggal 21 Februari 2021, Pukul 15.00 WIB.

Kusuma, S. (2017): Pengenalan dasar program ETABS. https://docplayer.info/55964588-

Pengenalan-dasar-programetabs.html\#: :text=1\%20PENGENA LAN\%20DASAR\%20PROGRAM\% 20ETABS,Barkeley\%2C\%20Califor nia\%2C\%20Amerika\%20Serikat.Dia kses pada 28 November 2020, Pukul 09.42 WIB.

Lastiasih, Y. dan Mochtar, B.I. (2008). Usulan

metoda perhitungan interaktif struktur pondasi di

atas tanah lunak dengan menyertakan pengaruh

penurunan konsolidasi jangka panjang. https://ejournal.undip.ac.id/index.php /mkts/article/view/3691. Diakses pada 02 Oktober, Pukul 09.42 WIB.
McCormac, C.J. (2003): Desain beton bertulang

edisi kelima. Jakarta: Erlangga

Pranoto, Y. dan Setiabudi, R. (2017): Evaluasi penurunan gedung dan metode perbaikannya (studi kasus: kantor pos Balikpapan). https://media.neliti.com/media/public ations/177026-ID-evaluasi penurunan-gedung-dan-metodeper.pdf. Jurnal 06. Diakses pada 01 Oktober, pukul 12.45 WIB.

Wibisono, K. (2009):Hasil audit gedung BNI Semarang diserahkan ke Kejati. https://www.antaranews.com/berita/2 061/hasil-audit-gedung-bnisemarang-diserahkan-ke-kejati.

Diakses pada 06 Desember 2020, Pukul 14.16 WIB

Zuhri. (2011): Perancangan struktur gedung kampus di kota Palembang Sumatera Selatan. Tugas Akhir Program Studi Teknik Sipil. Universitas Atma Jaya Yogyakarta. Halaman $30 . \quad \mathrm{http}: / / \mathrm{e}-$ journal.uajy.ac.id/10520/. Diakses pada 03 Desember 2020, Pukul 19.13 WIB. 